\title{
HIV-1-associated PKA acts as a cofactor for genome reverse transcription
}

\author{
Charline Giroud, Nathalie Chazal, Bernard Gay, Patrick Eldin, Sonia Brun and Laurence Briant ${ }^{*}$
}

\begin{abstract}
Background: Host cell proteins, including cellular kinases, are embarked into intact HIV-1 particles. We have previously shown that the Ca catalytic subunit of CAMP-dependent protein kinase is packaged within HIV-1 virions as an enzymatically active form able to phosphorylate a synthetic substrate in vitro (Cartier et al. J. Biol. Chem. 278:35211 (2003)). The present study was conceived to investigate the contribution of HIV-1-associated PKA to the retroviral life cycle.

Results: NL4.3 viruses were produced from cells cultured in the presence of PKA inhibitors H89 (H89-NL4.3) or Myr-PKI (PKI-NL4.3) and analyzed for viral replication. Despite being mature and normally assembled, and containing expected levels of genomic RNA and RT enzymatic activity, such viruses showed poor infectivity. Indeed, infection generated reduced amounts of strong-strop minus strand DNA, while incoming RNA levels in target cells were unaffected. Decreased cDNA synthesis was also evidenced in intact H89-NL4.3 and PKI-NL4.3 cell free particles using endogenous reverse transcription (ERT) experiments. Moreover, similar defects were reproduced when wild type NL4.3 particles preincubated with PKA inhibitors were subjected to ERT reactions.

Conclusions: Altogether, our results indicate that HIV-1-associated PKA is required for early reverse transcription of the retroviral genome both in cell free intact viruses and in target cells. Accordingly, virus-associated PKA behaves as a cofactor of an intraviral process required for optimal reverse transcription and for early post-entry events.
\end{abstract}

Keywords: HIV, Reverse transcription, cAMP-dependent kinase

\section{Background}

Reverse transcription is a key step in early replication of the human immunodeficiency virus type 1 (HIV-1) (for review see [1]). Once entered in the cell cytoplasm, the single-stranded retroviral RNA genome is converted into a double-stranded DNA molecule capable to integrate into the host genome. The reverse transcription is primed by a human RNA $^{\text {Lys3 }}$ primer packaged in virions that anneals to the primer binding site (PBS) and to an 8 nucleotide base-paired sequence upstream of the PBS known as the primer activation signal. The elongation reaction is catalyzed by the viral reverse transcriptase (RT), a heterodimeric enzyme formed of the p66 subunit that displays RNA-dependent DNA polymerase and RNase $\mathrm{H}$ activities, associated with the p51 subunit devoid of enzymatic

\footnotetext{
* Correspondence: laurence.briant@cpbs.cnrs.fr

Centre d'étude d'agents Pathogènes et Biotechnologies pour la Santé (CPBS)-CNRS UMR 5236, Université Montpellier 1,2, 1919 route de Mende, Montpellier, cedex 2 34293, France
}

activity. The minus-strand DNA is first synthesized by copying a short sequence at the $5^{\prime}$ end of the RNA genome complementary to the $\mathrm{R}$ and $\mathrm{U} 5$ regions. This step gives rise to the minus-strand strong stop DNA ((-)ssDNA)). Concomitantly with the elongation reaction catalyzed by the RT, the genomic RNA is degraded by RNase $\mathrm{H}$ activity of RT. Then the template is transferred to the 3' end of the genome in a reaction facilitated by annealing of the complementary $\mathrm{R}$ regions. This strand transfer allows the regeneration of the long terminal repeat sequences. Synthesis of the plus-strand DNA $((+) s s D N A)$ is initiated from the PPT fragment of genomic RNA and is extended by RT using a template consisting of $(-)$ ssDNA. The final full length double-stranded (FL) DNA is generated after a second template switch with each strand using other as a template. 
In infected cells, FL DNA synthesis is assisted by HIV1 encoded proteins present in the reverse transcription complex (RTC). Among them, the nucleocapsid protein (NC) is required for the initiation, chaperoning strand transfer and spatio-temporal control of the reaction $[2,3]$. Expression of Tat and physical contacts of RT with integrase and $\mathrm{Vpr}$ are also required for efficiency initiation of cDNA synthesis [4-6]. Finally, Nef and Vif proteins enhance RT affinity for the RNA genome and allow temporal regulation of RNA dimerization during early RT reaction [7-10]. In spite of the amount of information available on the mechanisms of HIV-1 DNA synthesis, many of the post-entry events that regulate the reverse transcription of HIV-1 genomic RNA remain unsolved (reviewed in [11]). As an example, the exact place where RT occurs in the infected cell cytoplasm, as well as the context in which proviral DNA is produced remains unknown. Ex vivo endogenous reverse transcription assays (ERT) helped clarifying some aspects of the reverse transcription process. First, this experimental approach pointed that the RT reaction is initiated and can proceed in the intact viral particle [12]. Indeed, (-)ssDNA, first-strand transfer and full-length minus strand products are detected in intact core fractions following incubation of the viral particle with deoxynucleotides (dNTPs). Hence, the biochemical activities necessary for the completion of early HIV-1 plus strand synthesis to the second-strand transfer step are retained in the core particle. Second, a direct correlation exists between HIV-1 capsid core organization and reverse transcription. This concept is supported by the critical morphological modifications of the retroviral core, including dissolution of the p24shelled viral core and absence of the core-envelope linkage region, observed following intravirion reverse transcription [13]. Moreover, recent quantification of RT DNA intermediates produced in assembled HIV-1 particles revealed that ERT activity is increased in viral particles incubated with mild concentration of detergent [14]. Disruption of the HIV-1 core, by mean of high concentrations of detergents was, in contrast, coincident with the loss of the ERT activity of virions, particularly with a significant reduction of late reverse transcription products synthesis [14]. This aspect is reminiscent of the inability of p24 mutants with alteration in core stability to perform reverse transcription [15]. The persistence of an assembled core structure may therefore benefit to the reverse transcription process. Third, it is also clear that reverse transcription most likely involves host cell cofactors. The significant enhancement of first-strand transfer and late RT products synthesis evidenced in ERT assay performed in the presence of cell extracts supports the contribution of cell encoded proteins in assisting the reverse transcription reaction $[14,16]$. Some of the cofactors required for proviral DNA synthesis are recruited to the reverse transcription complex (RTC) independently of interactions with HIV-1 RT. This is illustrated by the capacity of the survival motor neuron (SMN)-interacting protein 2 (Gemin2), an HIV-1-integrase binding protein, to enhance the assembly of RT on viral RNA in vitro and to stimulate (-)ssDNA production in vivo $[17,18]$. A similar contribution was also reported for integrase interactor 1 (INI1, hSNF5) [19,20], sin3A-associated protein (SAP18) and histone deacetylase 1 (HDAC1) [21]. Recruitment to the RTC of the human topoisomerase Topol and of the DHX9 RNA helicase packaged into HIV-1 particles through interaction with $\mathrm{NC}$ and Gag respectively, is also required for optimal reverse transcription reaction [22,23]. Recently, two subunits of the eukaryotic elongation factor 1, eEF1A and eEF1G interacting with p51 RT subunit and the retroviral integrase were reported to assist completion of reverse transcription by stabilizing the RTC in the cytoplasm of the infected cells [24]. A number of cofactors assisting early steps of HIV-1 replication were also identified by recent genomic screens [25-27]. Among them, RNA helicase and DNA repair activities were shown to physically interact with RT and to assist early post entry steps. Some of these studies, together with two-hybrid experiments, also pointed the requirement for A-kinase anchoring protein (AKAP) proteins, a family of proteins ensuring localization of the cAMP-dependent protein kinase to cellular membranes, to assist early HIV-1 DNA synthesis. Indeed, both AKAP13 knock down and inhibition of AKAP149/RNase $\mathrm{H}$ domain of $\mathrm{RT}$ interaction were reported to be deleterious for optimal reverse transcription [25,28]. The exact role of AKAPs in reverse transcription still remains unelucidated. Of note, in addition to RT cellular cofactors, host proteins counteracting HIV-1 reverse transcription have also been identified in the cell cytoplasm. The category of proteins is mainly represented by APOBEC3G. This cytidine deaminase both generates hypermutation of the newly synthesized (-) strand DNA [29-31] and interferes with RT displacement along the template by a cytidine-deaminase independent mechanism [32,33].

Here, we show that the catalytic subunit of the cAMPdependent protein kinase (PKA) packaged into HIV-1 viral particles acts as a cofactor for reverse transcription. Our previous observations have established that the $\mathrm{C} \alpha$ catalytic subunit of PKA packaged into viruses is required for viral infectivity [34]. The present study demonstrates that HIV-1 particles with reduced virus-associated PKA activity, display mature protein profile and have no apparent alteration in morphology. They contain wild type genomic RNA levels and reverse transcriptase activity, but are severely impaired for synthesis of $(-)$ ssDNA and production of subsequent RT intermediates in infected cells. Using endogenous reverse transcription (ERT) experiments, we provide evidence that PKA is required for optimal RT reaction in cell free particles. These results provide new insight into the mechanisms of HIV-1 reverse transcription. 


\section{Results \\ Phenotypic characterization of HIV-1 particles produced from PKA-deficient cells}

The catalytic subunit of PKA is packaged into HIV-1 particles. We have previously demonstrated that cultivation of HIV-1 infected cells with H89, a chemical competitive inhibitor of ATP that blocks PKA activity, leads to the production of particles containing reduced virus-associated PKA activity and display poorly infectivity [34]. The present study was designed to extend these observations and to investigate the contribution of virus-associated PKA in HIV1 life cycle. The number of encapsidated kinases identified so far in purified HIV-1 particles is limited, and PKA appears to be the unique packaged host-cell kinase susceptible to H89 inhibition (for review see [35]). Nevertheless, since kinase inhibitors generally display large inhibition spectra, we reconsidered our strategy and used genetic approaches, siRNA transfection and expression of dominant negative mutants, to extinguish PKA expression in HIV-1 producing cells. However, both approaches resulted only in partial inhibition of PKA in the HIV-1 producing cell (Additional file 1: Figure S1). According to this reproducible result, we rather conceived a strategy based on the use of Myr-PKI, a highly specific cell permeable peptide corresponding to the active domain of an endogenous PKA inhibitor [36]. HIV-1 particles were produced by transfection of the pNL4.3 molecular clone in 293T cells cultured in the presence of Myr-PKI using experimental procedures described elsewhere [34]. Similar experiments performed in the presence of H89 inhibitor were run in parallel. Concentrations of inhibitors used in these experiments were controlled to reduce significantly the cAMP-stimulated PKA activity in the producing cells using an in vitro kinase assay (Additional file 2: Figure S2A). Viral particles released from these cells were next subjected to sucrose cushion ultracentrifugation and normalized according to p24 content. In agreement with our previous observations [34], lysate of NL4.3 particles produced in absence of inhibitor efficiently phosphorylated a PKA peptide-substrate in in vitro kinase experiments (Additional file 2: Figure S2B). Addition of $20 \mu \mathrm{M}$ cAMP to the reaction was unable to enhance substrate phosphorylation, confirming that HIV-1associated PKA is incorporated into HIV-1 particles in an active form as previously reported [34]. In similar experimental conditions, normalized amounts of lysed viruses produced in the presence of Myr-PKI or H89 inhibitors, referred below as PKI-NL4.3 and H89-NL4.3 respectively, displayed reduced virus-associated PKA activity (Additional file 2: Figure S2B). Next, infectivity of virus preparations was tested using the MAGIC-5B indicator cell line expressing a $\beta$-galactosidase reporter gene under the control of HIV-1 LTR [37]. Infection levels were monitored by quantification of $\beta$-galactosidase activity in whole cell extracts. As presented in Figure 1A, infection of cells exposed to PKI-NL4.3 and H89-NL4.3 was approximately 8-10 times lower that observed from cells exposed to equivalent amounts of wild-type NL4.3 particles. The cAMP/PKA pathway is recognized to control HIV-1 transcriptional activity through TPA responsive elements (TRE)-like cAMP-responsive elements within the 5'untranslated (U5) leader [38]. Inhibition of cellular PKA activity could therefore decrease LTR-driven transcriptional activity in MAGIC-5B cells. Accordingly, we evaluated the possible interference of any contaminating PKA inhibitor that would have co-sedimented with viral preparation. Mock-transfected cells were maintained in the presence of H89 or Myr-PKI inhibitors in conditions identical to those used for virus production. Then, supernatants were subjected to sucrose cushion ultracentrifugation, pellets were resuspended and mixed with NL4.3 viruses produced from PKA proficient cells. Ratio of inhibitor-containing supernatants to NL4.3 particles was chosen to mimic viral preparations used in Figure 1A. Then the mixtures were incubated with MAGIC-5B cells. As shown in Figure 1B, no significant difference in HIV-1-induced LTR-driven $\beta$-galactosidase reporter gene expression was observed for NL4.3 and viral preparations supplemented with Myr-PKI- or H89-containing supernatants. Accordingly, reduced infectivity observed for H89-NL4.3 and PKINL4.3 preparations in Figure 1A could reasonably not be ascribed to contamination of viral preparation with cosedimented inhibitor.

\section{H89-NL4.3 and PKI-NL4.3 display distinct phenotypes in primary human $\mathrm{CD}^{+}$lymphocytes and macrophages}

Next, we tested whether viral phenotypes observed using the MAGIC-5B indicator cell line were conserved in primary human cells. PBMCs were prepared from blood samples from uninfected donor and $\mathrm{CD}^{+}$lymphocytes or macrophages were isolated using magnetic beads-conjugated $\mathrm{mAbs}$ directed to cell surface antigens and magnetic field separation. After activation, cells were infected with normalized amounts of NL4.3, H89NL4.3 or PKI-NL4.3. As attested by qPCR analysis, HIV-1 DNA levels were significantly reduced in PBMCs infected with H89-NL4.3 and PKI-NL4.3 as compared with copy number detected in cells infected with NL4.3 (Figure 2). A similar tendency was observed when $\mathrm{CD}^{+}$primary lymphocytes were processed in similar condition. Altogether, these data corroborate our previous observations [34] and indicate that NL4.3 viruses produced from cells with poor PKA activity are impaired for infectivity. To evaluate the role of HIV-1associated PKA in primary macrophages, CCR5-tropic NL81.A HIV-1 viruses were produced by transfection of HEK 293T cells cultured in the presence PKA inhibitors using above described experimental procedures. When used to infect macrophages, H89-NL81.A and 


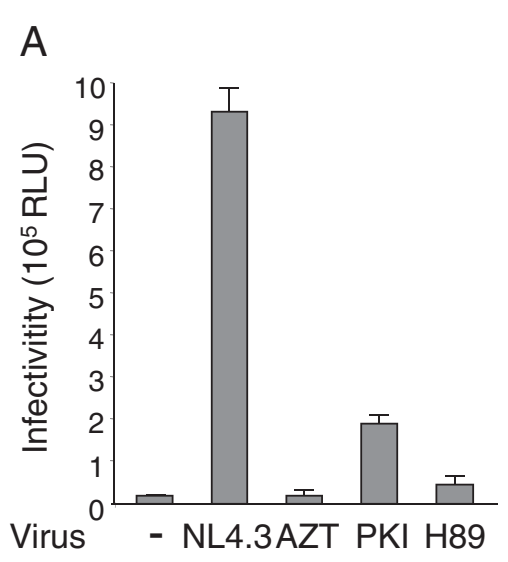

B

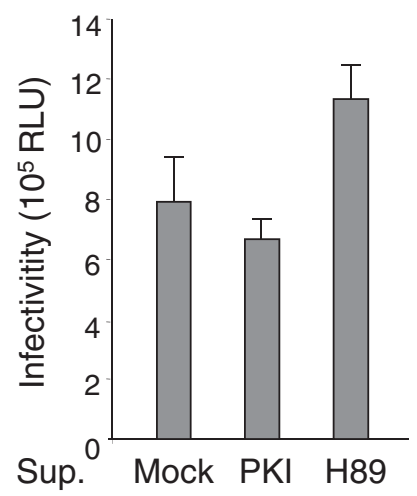

Figure 1 Infectivity of H89-NL4.3 and PKI-NL4.3. (A) Infectivity of normalized amounts of sucrose purified NL4.3, PKI-NL4.3 and H89-NL4.3 (10 ng p24 standardized to a final volume of $100 \mu \mathrm{L}$ ) was assayed in MAGIC-5B indicator cell lines. Control experiments consisted of mock infected cells (-) or NL4.3 infected cells maintained in the presence of $10 \mu \mathrm{M}$ AZT. Infectivity was quantified by $\beta$-galactosidase activity in total cell lysate. Each value represents an average of three experiments performed in triplicate \pm standard deviation. (B) Evaluation of viral samples contamination by co-purifying inhibitors. Supernatant (Sup.) of uninfected 293 cells maintained in medium alone (Mock) or cultured in the presence of $\mathrm{H} 89$ or Myr-PKI were subjected to gradient sucrose ultracentrifugation. Samples (100 $\mu \mathrm{L})$ were then mixed with NL4.3 viruses (10 ng p24) produced from PKA proficient cells and the mixture was used to infect MAGIC-5B cells. Infectivity was measured as described in (A).

PKI-NL81.A behaved as wild type NL81.A, generating comparable retroviral cDNA levels. Altogether, these data indicate that HIV-1 produced from PKA-deficient cells display similar phenotypes in MAGIC-5B indicator cells and in primary $\mathrm{CD}^{+}$lymphocytes. Defects accounting for

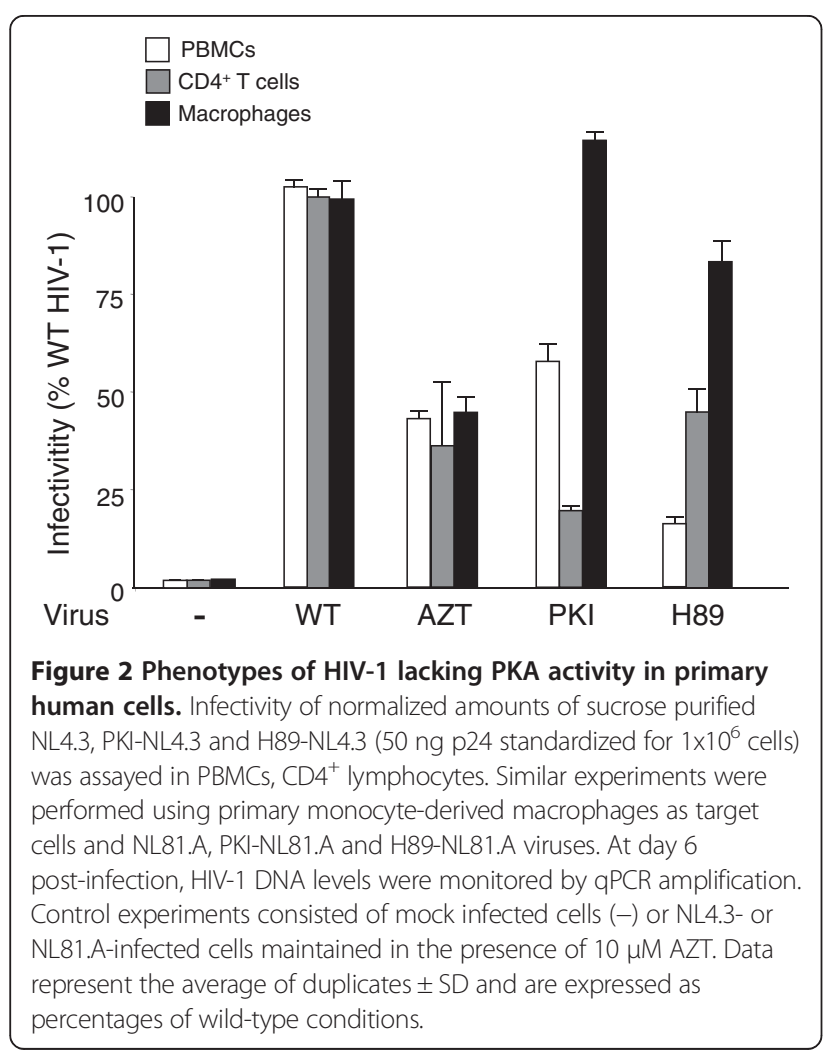

reduced viral replication in these cells were apparently efficiently compensated in macrophages since H89NL81.A and PKI-NL81.A replicated at wild type levels in these cells.

\section{H89-NL4.3 and PKI-NL4.3 viruses are fully mature and normally assembled}

In an attempt to investigate the nature of defects accounting for reduced infectivity of H89-NL4.3 and PKI-NL4.3 viruses, viral particles were next analyzed for protein content, maturation and assembly. Cell free particles or total extracts prepared from the corresponding producing cells were lysed and subjected to immunoblotting analysis. Samples were normalized according to total protein content for cell extracts and depending on the p24 concentration for viral particles preparations. Similar HIV-1 protein patterns were observed in cells cultured in absence or presence of PKA inhibitors. Regarding cell free particles, mature p24 was detected at similar levels in NL4.3, PKI-NL4.3 or H89NL4.3 particles. Also, levels of mature RT subunits and gp41 incorporation were similar in all viral samples analyzed (Figure 3A). Real time reverse transcription PCR (qRT-PCR) analysis revealed that genomic RNA was packaged with similar efficiency in NL4.3, PKI-NL4.3 and H89NL4.3 viruses (Figure 3B). Finally, electron microscopy imaging of individual particles revealed no visible difference in morphology, size or maturation between these viruses (Figure 3C and 3D). Accordingly, infectivity defects observed for NL4.3 viruses produced in the presence of MyrPKI or H89 could be inferred neither to alteration of viral proteins incorporation or maturation, nor to impaired nucleic acid incorporation or to visible assembly modification. 


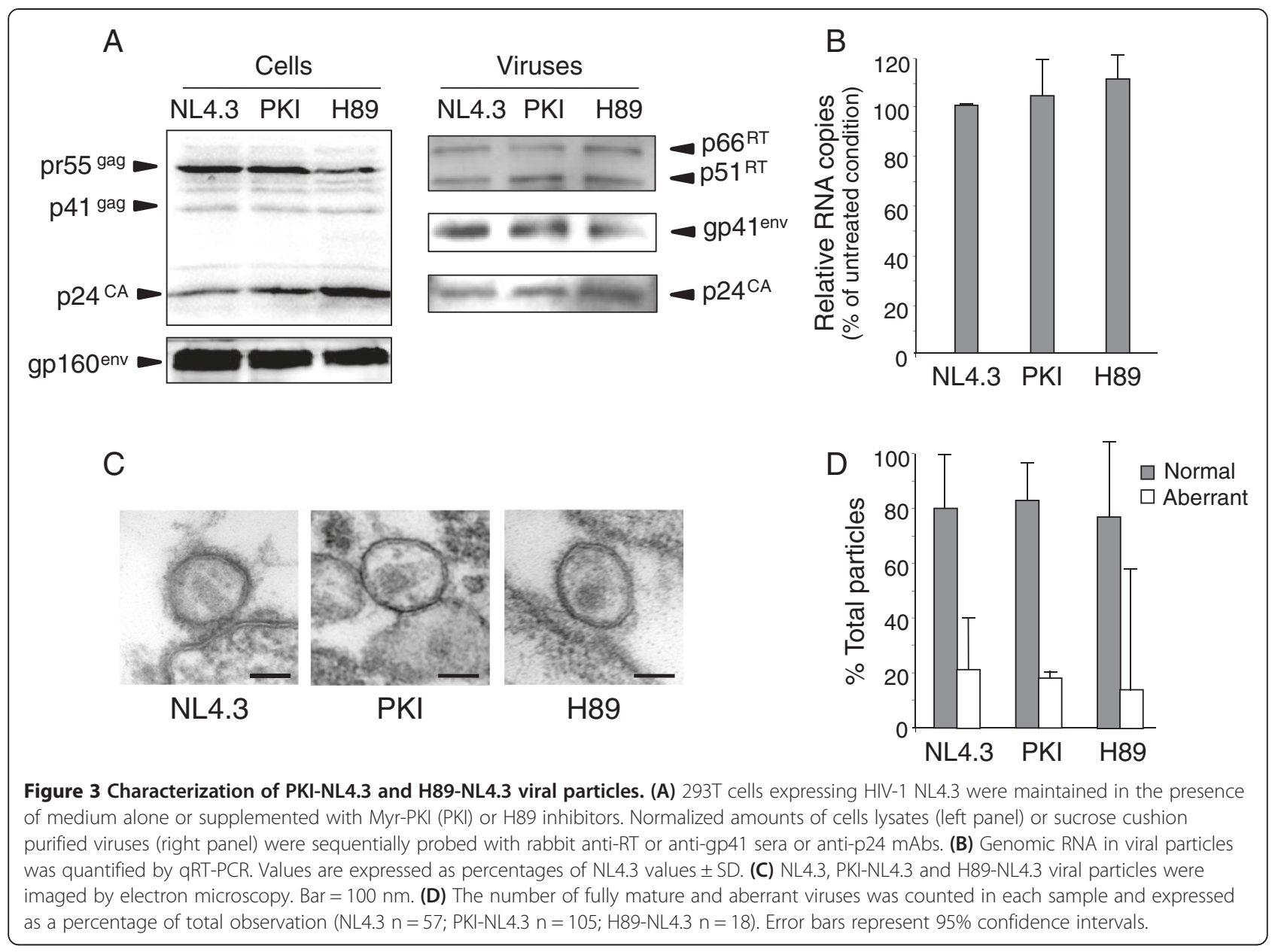

\section{Virus-associated PKA is required for HIV-1 genome reverse transcription}

Life cycle of H89-NL4.3 or PKI-NL4.3 viruses was next addressed by monitoring incoming genomic RNA in infected cells and quantifying cDNA intermediates synthesized during reverse transcription. First, levels of genomic RNA present in MAGIC-5B cells were quantified by qRTPCR. Samples were prepared 1 hour after viral exposure to avoid sample contamination with de novo synthesized viral mRNAs and infections were performed in the presence of $10 \mu \mathrm{M}$ AZT in order to prevent degradation of the RNA genome by the RT RNAse $\mathrm{H}$ activity during progression of the reverse transcription reaction. Similar RNA copy numbers were detected in cells infected with WT, H89-NL4.3 or PKI-NL4.3 viruses (Figure 4A). Preincubation of the cells with the T20 fusion inhibitor significantly reduced genomic RNA levels detected in the cells following infection with any virus tested, attesting for the specificity of our data. Because all viruses could enter target cells equally well, the rate and extent of reverse transcription performed by these viruses were analyzed by qPCR amplification of DNA intermediates 24 hours post-infection. In these experiments, viruses were treated with DNAse-I before addition to MAGIC-5B cells to remove any contaminant plasmid DNA in viral preparations. As shown in Figure $4 \mathrm{~B}$, the amount of (-)ssDNA detected in cells infected with H89-NL4.3 or PKI-NL4.3 was 5 to $15 \%$ that quantified in cells infected with NL4.3. A similar reduction was observed when the late RT product, second strand transfer DNA, was amplified. As expected, control consisting of cells infected with NL4.3 maintained in the presence of $10 \mu \mathrm{M}$ AZT immediately after virus challenge showed reduced levels of both early and late reverse transcription intermediates. Altogether these data indicate that H89NL4.3 and PKI-NL4.3 viruses efficiently infect their target cells, but are impaired for early reverse transcription.

\section{H89-NL4.3 and PKI-NL4.3 viruses display wild type intrinsic reverse transcriptase activity}

DNA synthesis defects evidenced for H89-NL4.3 and PKINL4.3 viruses reflect an impairment of the reverse transcription reaction. Therefore, we analyzed the enzymatic activity of reverse transcriptase packaged in H89-NL4.3 and PKI-NL4.3. Viral particles were lysed in the presence of NP-40 and incubated with a mixture of exogenous poly(rA)/oligodT template/primer hybrid and dNTPs. In 

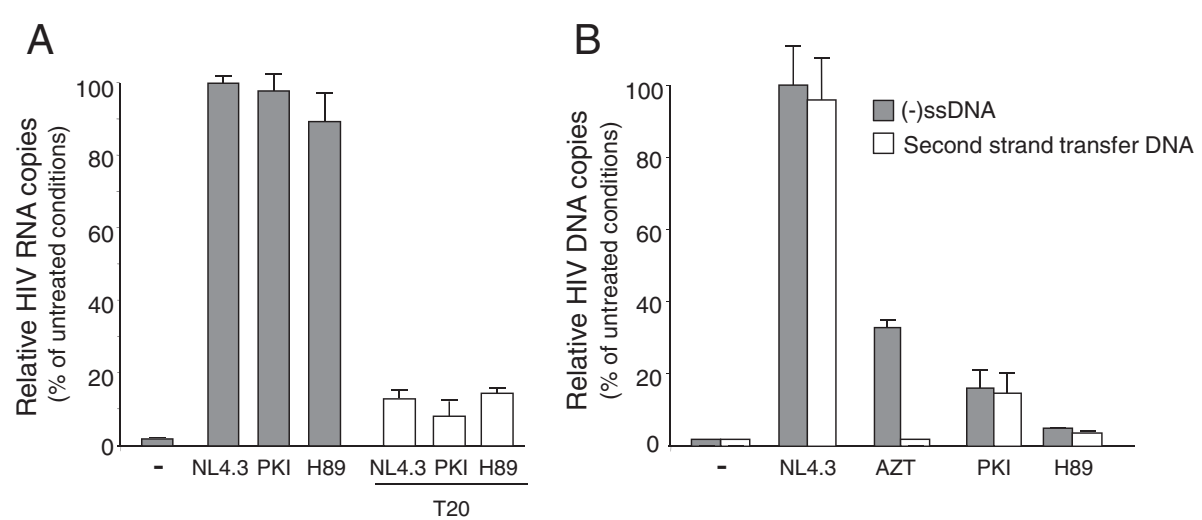

Figure 4 Quantification of genomic RNA and reverse transcription intermediates in cells infected with NL4.3, PKI-NL4.3 or H89-NL4.3 viruses. MAGIC-5B cells were infected with normalized amounts of NL4.3, PKI-NL4.3 or H89-NL4.3. Levels of genomic RNA (A) or (-)ssDNA or second strand transfer CDNA (B) in the infected cells were monitored by qRT-PCR or qPCR respectively. Control experiments consisted of mock infected cells (-) or NL4.3 infected cells maintained in the presence of $10 \mu \mathrm{M}$ AZT. Values are expressed as percentage of NL4.3 conditions \pm SD. Specificity of qRT-PCR detection of genomic RNA was controlled by preincubation of the cells for $30 \mathrm{~min}$ at $37^{\circ} \mathrm{C}$ in the presence of $1 \mu \mathrm{g} / \mathrm{ml} \mathrm{T20}$ fusion inhibitor before virus exposure.

these conditions, the RT activity, measured as the amount of dNTP incorporated into the template, was identical for normalized amounts of the three viruses (Figure 5A). To analyze further whether virus-associated PKA activity was required for activity of the reverse transcriptase, we repeated RT assays using lysate of NL4.3 viruses supplemented with inhibitory concentrations of Myr-PKI or
H89. As shown in Figure 5B, RT-catalyzed cDNA synthesis from a synthetic template/primer was identical in presence or in absence of inhibitor. As expected, nevirapine, an inhibitor of RT, used in the same conditions almost completely inhibited the exogenous RT reaction. Accordingly, enzymatic activity of the HIV-1 reverse transcriptase does not require a functional PKA.
A

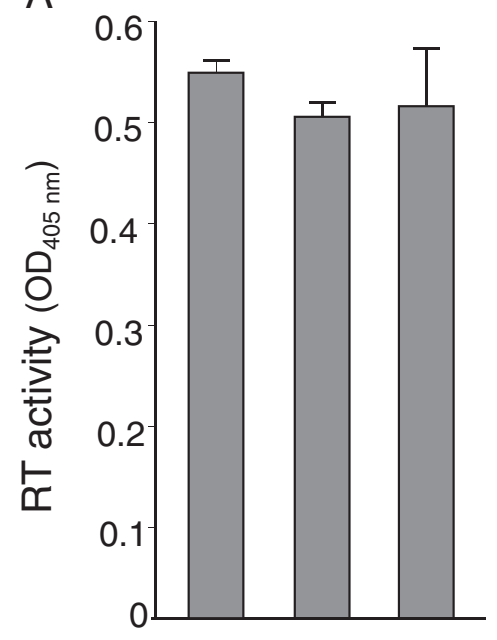

Virus NL4.3 PKI H89

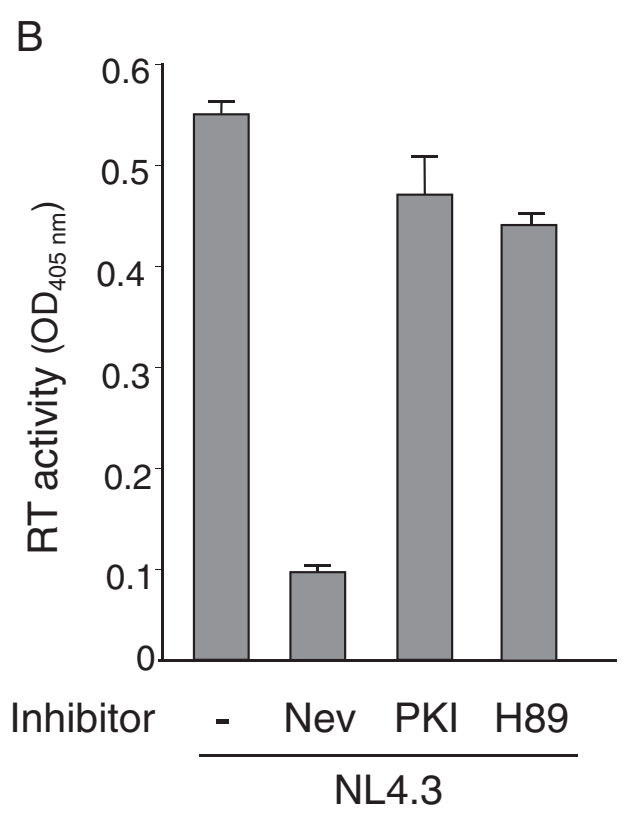

Figure 5 Quantification of intrinsic RT activity contained in NL4.3, H89-NL4.3 and PKI-NL4.3 particles. (A) Normalized amounts of sucrose-purified NL4.3, PKI-NL4.3 or H89-NL4.3 viruses were lysed and subjected to RT reaction in the presence of exogenous poly(A)/oligo dT template/primer hybrid and dNTPs. (B) RT reactions were performed with lysate of NL4.3 viruses incubated in the presence of H89 (100 $\mu \mathrm{M})$ or Myr-PKI $(50 \mu \mathrm{M})$ inhibitors. Addition of nevirapine (Nev) to the reaction mixture was used as a negative control. RT activity was quantified by ELISA as described in the Material and Methods section. Results are the mean of three separate experiments performed in triplicate \pm standard deviation. 


\section{Endogenous reverse transcription is impaired by PKA inhibitors}

Reverse transcription can be initiated by addition of dNTPs into intact or mildly permeabilized HIV-1 particles, leading to the synthesis of FL DNA $[12,16]$. This experiment, referred to ERT (endogenous reverse transcription) assay merely serves as a model for understanding the reverse transcription occurring inside target cells. When performed using intact viral particles or virions incubated with low detergent concentrations, it gives access to the ability of the machinery contained in virions to produce proviral DNA using the RNA genome as a template and the tRNA $^{\text {Lys3 }}$ primer [14]. To decipher with the RT defect observed for PKI-NL4.3 and H89-NL4.3 viruses, viral particles were subjected to ERT reactions. Sucrose purified particles were permeabilized by addition of $0.1 \mathrm{mM}$ Triton X-100 and incubated with dNTPs to allow synthesis of
cDNA. Addition of low Triton X-100 concentrations (up to $0.1 \mathrm{mM}$ ) to the reaction mixture was reported to enhance levels of proviral DNA by permeabilizing the virion to nucleotides without destabilizing the viral particle [14]. Then, the reaction products were extracted and quantified by qPCR. Using these conditions, (-)ssDNA was detected at very low levels in NL4.3 particles maintained in absence of dNTPs and was drastically enhanced by addition of dNTPs (Figure 6A). Synthesis was abolished by addition of the membrane permeable inhibitor of reverse transcriptase nevirapine to the mixture, attesting for the specificity of the reaction. Next, PKI-NL4.3 and H89-NL4.3 viruses were subjected to ERT reactions using similar experimental conditions. When compared with NL4.3 viruses, (-) ssDNA synthesis was reduced by $44 \%$ and $27 \%$ for PKINL4.3 and H89-NL4.3 particles respectively (Figure 6B). Accordingly, viral particles produced in the presence of
A

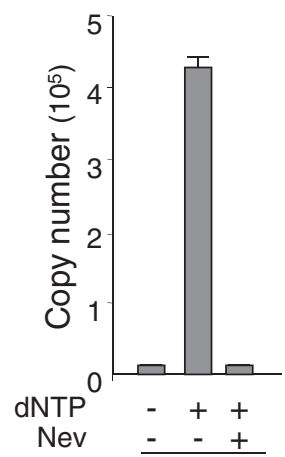

NL4.3

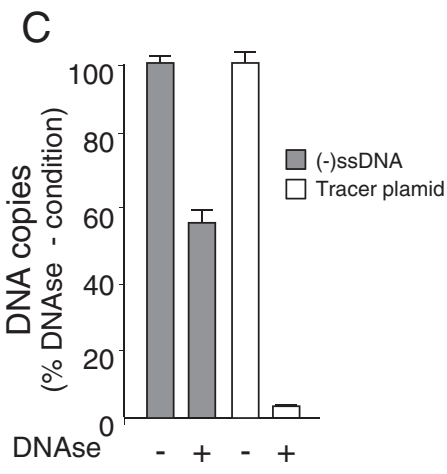

NL4.3
B

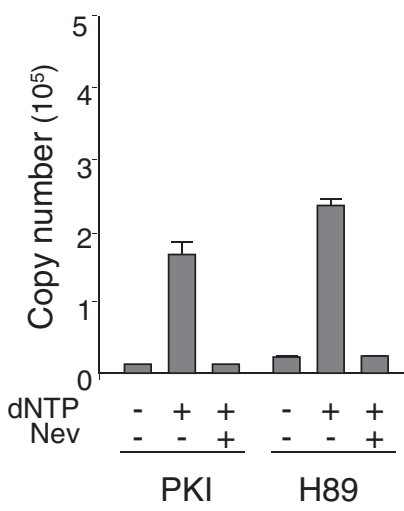

$\mathrm{D}$

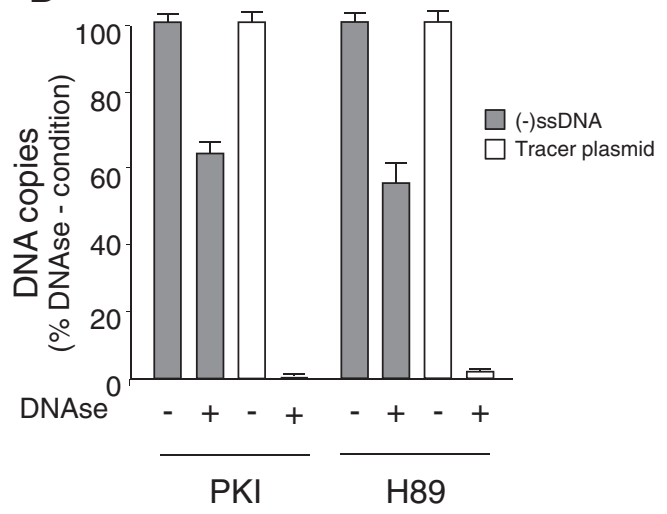

Figure 6 Synthesis of (-)ssDNA in permeabilized NL4.3, H89-NL4.3 and PKI-NL4.3 viruses. (A) Sucrose purified NL4.3 viruses permeabilized with $0.1 \mathrm{mM}$ Triton X-100 were subjected to ERT reactions run for $16 \mathrm{~h}$ in the presence or absence of dNTPs. Control experiments consisted of incubation of viruses with dNTPs and $20 \mu \mathrm{g} / \mathrm{mL}$ nevirapine (Nev). (-)ssDNA copy numbers were determined in each sample by qPCR. Values are expressed as absolute copy numbers. Error bars indicate standard deviations $(n=4)$. (B) PKI-NL4.3 or H89-NL4.3 particles were subjected to ERT reactions as described in (A). (C) and (D) Accessibility of ERT products synthesized in NL4.3, H89-NL4.3 and PKI-NL4.3 particles was monitored by addition $4 \cup$ DNase and $10^{5}$ copies of a tracer plasmid to the reaction mixture. After DNase inactivation and nucleic acids extraction, (-)ssDNA and tracer plasmid copy numbers were determined by qPCR. Values are expressed as a percentage of DNA levels detected in no DNAse reactions. 
PKA inhibitors are less efficient at producing (-)ssDNA in ERT reaction. To examine whether such defects were linked to modification of the integrity of viruses engaged in the reaction, ERT experiments were repeated and followed by a DNAse digestion step of the final reaction mixture. A tracer plasmid $\left(10^{5}\right.$ copies) was added to the mix to control the efficiency of DNAse treatment. Then, total DNA present in the reaction was extracted and both proviral DNA synthesized in viral particles and tracer plasmid were monitored by qPCR. In our experimental conditions, levels of tracer plasmid detected by qPCR were reduced to background level by DNAse treatment, attesting for the efficiency of the digestion step (Figure 6C). In contrast, (-) ssDNA detected in NL4.3 particles following addition of dNTPs were only reduced by $40 \%$, indicating that HIV- 1 cDNA remained mostly inaccessible to degradation by DNAse. Accordingly, as previously demonstrated by others Triton X-100 used at a $0.1 \mathrm{mM}$ concentration permeabilized the virions to nucleotides without totally disrupting the viral particles and allowed intraviral genome reverse transcription [14]. When applied to ERT products generated by Triton-permeabilized H89-NL4.3 or PKINL4.3 particles, DNAse I treatment reduced levels of (-) ssDNA and tracer plasmid in proportion similar to that observed for NL4.3 particles (Figure 6D). Therefore, the reduced capacity of H89-NL4.3 and PKI-NL4.3 viruses to produce (-)ssDNA in ERT experiments cannot be ascribed to drastic structural modification of the viral particles. Finally, to investigate whether the reduced efficiency of ERT observed in PKI-NL4.3 and H89-NL4.3 viruses was not due to any defect acquired during particles biogenesis, NL4.3 particles were subjected to ERT reaction performed in the presence of PKA inhibitors. The above-described experimental procedures were repeated starting from Triton X-100-permeabilized NL4.3 particles incubated in the presence of dNTPs, but reactions were supplemented with increasing concentrations of Myr-PKI or H89 before allowing viral DNA synthesis. As shown in Figure 7A and 7B, (-) ssDNA synthesis decreased as the concentration of $\mathrm{H} 89$ or Myr-PKI increased in the reaction (Figure 7A and 7B). The addition of $100 \mu \mathrm{M}$ H89 lowered ERT activity by $25 \%$ for H89 and Myr-PKI decreased (-)ssDNA synthesis by $70 \%$ when added at $50 \mu \mathrm{M}$. Accordingly, H89 and Myr-PKI likely inhibit an intraviral process in NL4.3 particles required for optimal efficiency of the early reverse transcription reaction.

\section{Discussion and conclusion}

The aim of this study was to decrypt the role played by HIV-1-associated PKA in virus infectivity. To this end we took advantage of our capacity to produce HIV-1 particles containing reduced PKA activity. This goal was previously achieved by mean of the cell-permeable H89 inhibitor of PKA [34]. To improve the specificity of our experimental
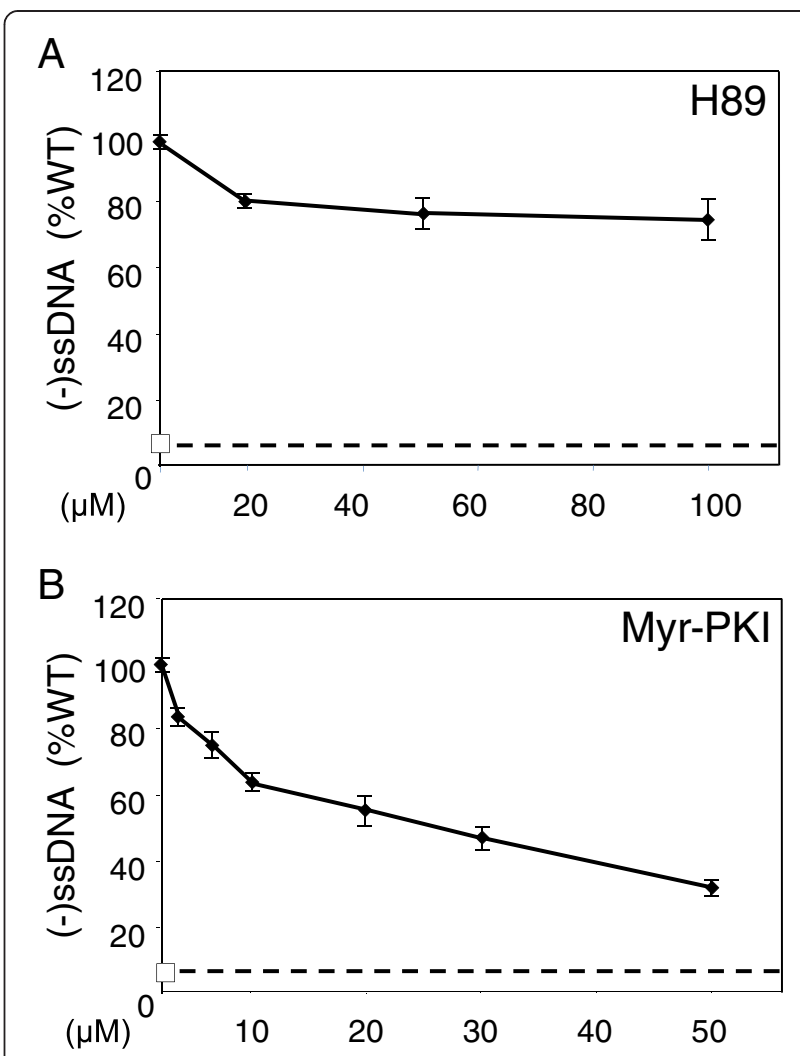

Figure 7 Contribution of virus-associated PKA activity in endogenous reverse transcription. NL4.3 viruses were subjected to ERT experiments run in the presence of dNTPs and increasing concentrations of $\mathrm{H} 89$ (A) or Myr-PKI (B). For each reaction, nucleic acids were extracted and (-)ssDBNA production was quantified by GPCR amplification. DNA levels detected in ERT reactions performed in the presence of nevirapine are indicated by a dotted line. Data are mean values of duplicate experiments and are expressed as a percentage of WT conditions.

model, we initially focused on the use of siRNA targeting mRNA encoding the C $\alpha$ catalytic subunit of PKA. Unfortunately, despite reducing significantly intracellular PKA levels, a basal expression remained in the producing cells that accounted for residual PKA incorporation into virions. These viral particles were approximately $40 \%$ less infectious than normalized amounts of wild type HIV-1. Similarly, ectopic expression of a D324G mutant of PKARI $\alpha$ regulatory subunit, that is unable to dissociate from PKA catalytic subunit, resulted in an intermediate phenotype (Additional file 1: Figure S1). Accordingly, this strategy was abandoned in favour of the use of chemical inhibitors whose capacity to inhibit PKA rely on distinct mechanisms. Myr-PKI is a myristoylated peptide which contains a PKA substrate consensus sequence with the serine phosphoracceptor site replaced by alanine [36]. This peptide inhibits PKA enzymatic activity and displays high selectivity by docking to the substrate binding site of the kinase [39]. The parallel use of Myr-PKI with that of H89, a competitive 
inhibitor of ATP during kinase activation, therefore limits the risk to focus on off target effects resulting from wide spectrum kinase inhibitory properties.

Here we found that HIV-1 particles produced from virus-expressing cells cultured in the presence of H89 or Myr-PKI concentration effective at inhibiting cellular PKA activity were fully mature and displayed no apparent assembly defect. Particularly, they contained expected levels of mature p51 and p66 RT subunits and intrinsic RT activity was unaffected as evidenced in exogenous RT assays performed using a synthetic poly(rA)/oligodT template. Moreover, genomic RNA content was comparable to that of wild type NL4.3 particles. H89-NL4.3 ad PKI-NL4.3 viruses efficiently infected targets cells as supported by the levels of incoming genomic RNA in cell extracts. However, these viruses displayed reduced infectivity and were unable to reverse transcribe the viral genome into FL proviral DNA. Indeed, viruses were defective for (-)ssDNA production indicating that an early step of the reverse transcription process was impaired. Testing of intrinsic RT activity associated with H89-NL4.3 and PKI-NL4.3 viruses together with experiments based on incubation of wild type RT in the presence of chemical inhibitors revealed that reverse transcriptase enzymatic activity was unaffected by PKA perturbators. Nevertheless, H89-NL4.3 and PKI-NL4.3 viruses displayed a reduced capacity to produce (-)ssDNA in ERT, when incubated with dNTPs in conditions maintaining the integrity of viral particles. Accordingly, such viruses were defective for an intraviral process required for optimal reverse transcription. Interestingly, ERT could be inhibited in NL4.3 particles by addition of PKA inhibitors to the reaction mixture. Therefore, the possibility that the decreased DNA synthesis evidenced for H89-NL4.3 and PKI-NL4.3 viruses in ERT experiments is consecutive to an interference with intracellular assembly in cell cultured in the presence of PKA inhibitors can be reasonably rejected. As PKA is incorporated in an active form in HIV-1 particles [34], our data support that the virus-associated kinase is required either to produce a functional reverse transcription complex in the viral particle or to create the appropriate microenvironment required for optimal reverse transcription.

The exact contribution of PKA in proviral DNA synthesis needs further investigation. A number of studies have indicated that p51 and p66 subunits of HIV-1 reverse transcriptase are post-translationally modified in virions, infected cells and RTCs $[40,41]$. Such modifications enhanced reverse transcription efficiency and progression. However, the contribution of PKA in RT phosphorylation was rejected [42]. Nevertheless, it remains possible that virus-associated PKA could modify a virus-incorporated HIV-1 encoded protein assisting reverse transcription. In this context, the role of Nef and Vpr, two PKA-phosphorylated proteins both known to be required for proviral DNA synthesis, needs to be investigated [43,44]. A possible regulation of RT through modulation of the APOBEC3G/Vif interplay should also be considered as PKA-mediated phosphorylation of APOBEC3G can regulate the interaction between A3G and Vif [45]. In addition, the capacity of PKA to phosphorylate the HIV-1 p24 protein in vitro and to interact with PKA in vivo has to be kept in mind [34]. Indeed, substitution mimicking phosphorylation of serine residues identified as phosphoacceptor sites either in the p24 interdomain linker or in helix 9 , a dimerization interface required for core assembly, inhibits reverse transcription [46]. Such mutations rendered the HIV-1 core unstable and generated mild assembly defects. According to these data, and to data presented herein, HIV-1-associated PKA could fulfill a complex role during post-entry steps of HIV-1 infection through the phosphorylation of multiple targets thereby creating a microenvironment that favours the initiation and the progression of the reverse transcription. A series of experiments is under progress to test these hypotheses.

Finally, phenotypes observed for H89-NL4.3 and PKINL4.3 viruses differed according to the target cell. RT defects observed in indicator cells and $\mathrm{CD}^{+}$lymphocytes were efficiently compensated in macrophages, allowing synthesis of wild type levels of proviral DNA. Suppressing host cell cAMP-dependent PKA activation by $\beta$-chemokines (MIP-1 $\alpha$, MIP1- $\beta$ and RANTES) was previously reported to inhibit HIV-1 cDNA synthesis in primary $\mathrm{CD} 4^{+}$lymphocytes but not in macrophages [47]. In agreement with these observations, our data indicate that HIV-1-associated PKA might exert differential effects in primary lymphocytes and macrophages and that post-entry steps may significantly differ in these two cell types.

Overall, a complex interplay between PKA and HIV-1 infection has been reported in the literature. Increased intracellular levels of cAMP and constitutive activation of PKA were measured in cells from HIV-1 infected patients [48]. Such defect correlated with $\mathrm{T}$ cells dysfunction and immunodeficiency [48-50]. To the opposite, reduction of intracellular cAMP levels or PKA agonists restores immune responses in $\mathrm{T}$ cells isolated from HIV-1 infected patients through the inhibition of the cAMP/PKA pathway $[48,51]$. At the cell level, modulation of the cAMP/PKA pathway was reported to enhance HIV-1 replication at multiple steps, including LTR-driven HIV genes transcription $[47,52,53]$ and proviral DNA synthesis $[47,52,53]$. Here, we showed that incorporation of an active PKA determines the efficiency of early steps of reverse transcription in a new target cell. In light of these observations, both the PKAdependent pathway in the target cell and virus-associated PKA represent key players in HIV-1 replication and pathogenesis. This model agrees with the results of recent metaanalysis of genome-wide studies that identified PKA as an important host factor in early HIV-1 replication [26]. 


\section{Methods \\ Cells}

Human embryonic kidney 293T cells and the MAGI-5B indicator cell line [37] were cultured in Dulbecco's modified Eagle's medium (Life Technologies, Inc.) supplemented with $10 \%$ fetal calf serum (Cambrex), 100 units $/ \mathrm{mL}$ penicillin, $100 \mu \mathrm{g} / \mathrm{mL}$ streptomycin. Peripheral blood mononuclear cells (PBMCs) from healthy donors were isolated from buffy coats by Ficoll-Hypaque gradient centrifugation. $\mathrm{CD}_{1}{ }^{+}$monocytes were isolated with anti-human CD14coated magnetic beads (Miltenyi Biotec) according to manufacturer recommendations and differentiated into macrophages by incubation for 5 days in complete medium (RPMI $1640-10 \%$ fetal calf serum) supplemented with hM-CSF (Immunotools). CD4 ${ }^{+} \mathrm{T}$ cells were isolated from CD14 - peripheral blood lymphocytes with a $\mathrm{CD}^{+}{ }^{+} \mathrm{T}$-cell enrichment kit (Stem Cell Technologies). Cells were then resuspended in RPMI 1640 medium supplemented with $10 \%$ heat-inactivated fetal calf serum and stimulated for 3 days with $5 \mu \mathrm{g} / \mathrm{ml}$ phytohemagglutinin in the presence of $20 \mathrm{U} / \mathrm{ml}$ of interleukin-2 (Roche).

\section{Viral stock production}

Viral stocks were generated as previously described [34]. 293T cells $\left(5 \times 10^{6}\right)$ were transfected with $30 \mu \mathrm{g}$ of pNL81.A (kindly provided by W.C. Greene) or pNL4.3 DNA (AIDS Research and Reference Reagent Program, Division of AIDS, NIAID, NIH) using calcium phosphate precipitation. Twenty-four hours post transfection, the cells were extensively washed and cultured for an additional $16 \mathrm{~h}$ in medium alone or supplemented with $100 \mu \mathrm{M} \mathrm{H} 89$ (Sigma-Aldrich) or with $50 \mu \mathrm{M}$ Myr-PKI peptide (Myr- $\left.{ }_{14} \mathrm{GRTGRRNAI}_{22}-\mathrm{NH} 2\right)$ (SigmaAldrich). Virus-containing supernatants were collected, filtered onto $0.45 \mu \mathrm{m}$ membranes. All viral preparations were purified by centrifugation through $20 \%$ sucrose cushion at $25,000 \mathrm{rpm}$ for $2.5 \mathrm{~h}$ at $4^{\circ} \mathrm{C}$ in a Sw32Ti rotor (Beckman Coulter, France). The pellets were resuspended in PBS, aliquoted and stored at $-80^{\circ} \mathrm{C}$. Viral stocks were normalized according to p24 content using an anti-p24 Enzyme-linked Immunosorbent Assay (Ingen, France).

\section{Viral infectivity assays}

MAGI-5B cells which stably express the $\beta$-galactosidase reporter gene cloned downstream of the HIV-1 LTR promoter were platted at $8 \times 10^{3}$ cells $/ 100 \mu \mathrm{L}$ in 96 wells plates. The cells were exposed to viral solutions normalized according to $\mathrm{p} 24$ content. 48 hours post-infection, virus infectivity was monitored by measurement of $\beta$ galactosidase activity from the cell lysates as previously described using the Galactostar $\beta$-galactosidase assay kit (Applied Biosystem). Luminescence was recorded using a Centro XS3 LB960 luminometer (Berthold, France). Values were normalized according to protein content of the cell extract (BCA assay kit, Pierce). T20 fusion inhibitor was obtained from the AIDS Research and Reference Reagent Program (Division of AIDS, NIAID, NIH).

\section{Immunoblotting analysis}

Cell or sucrose-purified virions were solubilized in RIPA buffer and separated on a $12.5 \%$ SDS-PAGE. Proteins were transferred to PVDF membrane (Millipore) and revealed using a rabbit polyclonal serum directed to RT (kindly provided by J. L. Darlix, ENS, Lyon, France) or mAbs raised against CA (Biogenesis) or anti-gp41 (Fitzgerald Inc.). Secondary antibodies conjugated to horseradish peroxidase were revealed by enhanced chemiluminescent detection (Pierce Biotechnology Inc.).

\section{Electron microscopy analysis}

Virus-producing cells were processed for thin-layer electron microscopy as described elsewhere [34]. Briefly, the cells were fixed in situ with $2.5 \%$ glutaraldehyde in cacodylate buffer ( $\mathrm{pH} 7.4)$ for $60 \mathrm{~min}$ at $4^{\circ} \mathrm{C}$. Cells were then postfixed with $2 \%$ osmium tetroxide, washed in cacodylate buffer containing $0.5 \%$ tanic acid, and embedded in epon (Embed-812, Electron Microscopy Sciences Inc.). Preparations were examined with a Hitachi H.7100 transmission electron microscope (CRIC, University Montpellier 1, France).

\section{qPCR analysis of genomic RNA and proviral DNA}

Total RNA isolated from cells challenged with HIV for $1 \mathrm{~h}$ or genomic RNA contained in HIV-1 particles (100 ng p24) was extracted with Tri-Reagent (Sigma, France) and subjected to qRT-PCR analysis as previously described [54]. Briefly, a poly(dT) olygonucleotide was used as RTprimer and subsequent qPCR was performed with a the SYBR $^{\circ}$ Green PCR Master Mix (Roche, France) on the RotorGene system (Labgene, France). A $90 \mathrm{bp}$ fragment in the R-U5 region from the HIV-1 RNA was amplified using 5'-AGCAGCTGCTTTTTGCCTGTA-3' and 5' -AAGCA GTGGGTTCCCTAGTTAG-3' oligonucleotides. A standard curve was generated from $10^{2}$ to $10^{6}$ copies of pNL4.3 plasmid. Each assay was accompanied by controls without reverse transcriptase (DNA contamination levels $<1 \%$ of HIV-1 RNA). The copy numbers of HIV-1 genomic RNA in cell samples were normalized to that of the GAPDH mRNA quantified in parallel as endogenous control.

For proviral DNA analysis, total DNA was extracted from cells infected for $24 \mathrm{~h}$ with DNAse I-treated virus, using the DNeasy extraction kit (Qiagen). In order to check for the absence of contaminating plasmid (pNL4.3 or pNL8.1A) in samples, DNA preparation were tested with a primer pair that specifically amplifies the pUC region of the molecular clone as previously reported [46], and all samples found positive were discarded. HIV-1 
DNA synthesis was then monitored by qPCR as described elsewhere [46]. Primers used for amplification were: (-) ssDNA: \#73: 5' -ACACAACAGACGGGCACACAC-3' and \#187: 5' - GGTCTCTCTGGTTAGACCA-3'; second strand transfer DNA \#169: 5'-AGCAGCTGCTTTTTGCCTGT A-3' and MA: 5'-CCTGCGTCGAGAGATCTCCTCGG-3'.

\section{Analysis of intrinsic reverse transcriptase activity}

Exogenous reverse transcription assays were performed to measure the enzymatic activity of the RT contained in lysate of viral particles ( $3 \mathrm{ng} \mathrm{p} 24)$ when incubated in the presence of synthetic poly(rA)-oligo(dT) template and primer using the Reverse transcriptase assay colorimetric kit (Roche, France).

\section{Endogenous reverse transcription assays (ERT)}

Proviral DNA synthesis in assembled viral particles permeabilized with reduced amounts of detergent was determined in ERT assays. This assay is based on the use of endogenous RNA genome as a template and that of the endogenous tRNA ${ }^{\text {Lys3 }}$ as a primer. Sucrose cushion-purified virus particles (normalized according to p24 content to $10 \mathrm{ng}$ ) were incubated for $18 \mathrm{~h}$ at $37^{\circ} \mathrm{C}$ in the presence of $0.1 \mathrm{mM}$ Triton X-100, $10 \mathrm{mM}$ Tris, $\mathrm{pH}$ 7.4, $10 \mathrm{mM} \mathrm{MgCl}_{2}$, and $200 \mu \mathrm{M}$ of each dNTP in a final volume of $50 \mu \mathrm{L}$. Nucleic acids were then extracted with DNeasy extraction columns (Qiagen) and eluted in $200 \mu \mathrm{L}$ of water. RT products were quantified by qPCR amplification using $2.5 \mu \mathrm{L}$ as template. As a control, the same mix was prepared for each sample but without dNTPs and a no-nucleotide control reaction mixture was always included. Accessibility of reverse transcription products to degradation after the permeabilization of virions with detergent was assayed by addition of $4 \mathrm{U}$ DNase I (Life Technologies) to the ERT products and incubation for $30 \mathrm{~min}$ at $37^{\circ} \mathrm{C}$ before nucleic acids extraction.

\section{Ethical approval}

Primary human cells used for this work were obtained from the French blood establishment (EFS, Toulouse, France) in accordance with international ethical principles and French national law under declaration $\mathrm{N}^{\circ}$ DC-2008-207 to the French Ministry of Research and Higher Studies.

\section{Additional files}

Additional file 1: Figure S1. siRNA against PKA-Ca or expression of dominant negative $\mathrm{Rl}$-a regulatory subunit in the producer cells reduce infectivity of NL4.3 particles. (A) MAGIC-5B cells were transfected with $50 \mathrm{nM}$ control siRNA (siC) or siRNA against PKA Ca subunit (siPKA) (Cell Signaling Technology) using Interferin transfection reagent (Polyplus Transfection). Seventy-two hours after transfection, the culture was infected with HIV-1 NL4.3 and viral particles released in supernatants during the next $12 \mathrm{~h}$ were collected. Infectivity of virus preparations (20 or 50 ng p24 standardized to a final volume of $100 \mu \mathrm{l}$ ) was assayed in MAGIC-5B indicator cell lines. Mock infected cells (-) are shown as control. Each value represents the mean of duplicate experiments \pm standard deviation. (B) Expression of PKA-Ca in virus-producing cells was monitored over time by immunoblot analysis. Proteins levels loaded in each line were monitored by incubation with anti-tubulin mAbs (Santa-Cruz Biotechnology, Inc.). (C) 293 T cells expressing the pNL4.3 HIV-1 molecular clone were transfected with the promoter inducible pPKA Rla $^{\text {D324G }}$ plasmid encoding a dominant negative (DN) regulatory subunit unable to release PKACa [55] (kindly provided by Pr. B. Schimmer, University of Toronto) or with an empty vector (Mock) and culture in the presence of

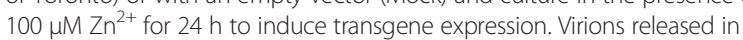
culture supernatant were normalized to $10 \mathrm{ng}$ p24 and used to infect MAGIC-5B cells. Infectivity was determined by quantification of reporter gene expression in cell lysates. PKA activity in the producing cells was determined using the MESACUP protein kinase assay kit (MBL, Ltd., Nagoya, Japan). Values are expressed as percentage of mock conditions.

Additional file 2: Figure S2. PKA is incorporated in an active form in NL4.3 but not in PKI-NL4.3 or H89-NL4.3 particles. (A) PKA activity in lysate of HIV-1-producing 293 T cells cultured in medium alone or in the presence of $\mathrm{H} 89$ or Myr-PKI was determined using the MESACUP protein kinase assay kit (MBL, Ltd., Nagoya, Japan). Addition of CAMP (20 $\mu \mathrm{M})$ to the reaction mixture was used to stimulate kinase activity. (B) Normalized amounts of purified NL4.3, PKI-NL4.3 and H89-NL4.3 viruses were lysed and analyzed for PKA activity. NL4.3-associated kinase activity remained unchanged when $20 \mu \mathrm{M}$ CAMP was added to the reaction mixture but was reduced by addition of $\mathrm{H} 89(20 \mu \mathrm{M})$ or Myr-PKI $(10 \mu \mathrm{M})$ to the reaction mix, attesting that PKA is incorporated into HIV-1 particles in an active form. In these experimental conditions, kinase activity associated with normalized amounts of PKI-NL4.3 or H89-NL4.3 lysates was significantly reduced as compared with that detected from NL4.3 particles.

\section{Abbreviations}

PKA: CAMP-dependent protein kinase; HIV-1: Human immunodeficiency virus type 1; PBS: Primer binding site; RT: Reverse transcriptase; RTC: Reverse transcription complex; ERT: Endogenous reverse transcription; (-) SSDNA: minus strand strong stop DNA; dNTPs: deoxynucleotides; TRE: TPA-responsive element; LTR: Long terminal repeat; CypA: Cyclophilin A; AZT: Azidothymidine; qPCR: quantitative PCR; VSV-G: Vesicular stomatitis virus glycoprotein $\mathrm{G}$.

\section{Competing interests}

The authors declare that they have no competing interest.

\section{Authors' contributions}

CG, PE and SB performed the experiments. BG performed the electron microscopy studies. NC and LB designed the experiments, analyzed the data and wrote the paper. All authors read and approved the final manuscript.

\section{Acknowledgements}

We are indebted to Georges Le Falher for technical assistance in preliminary experiments, to Stéphane Basmaciogullari (Université Paris Descartes, Paris) and to Mélanie Denizot (IRG, EA 451, University of La Reunion) for helpful discussions. This work was supported by institutional funds from CNRS and grants from ANRS and Sidaction. CG and SB were fellows of ANRS and of the CNRS-Région Languedoc Roussillon respectively.

Received: 8 June 2012 Accepted: 2 December 2013

Published: 17 December 2013

\section{References}

1. Abbink TE, Berkhout B: HIV-1 reverse transcription initiation: a potential target for novel antivirals? Virus Res 2008, 134:4-18.

2. Mougel $M$, Houzet $L$, Darlix $\lrcorner$ : When is it time for reverse transcription to start and go? Retrovirology 2009, 6:24.

3. Darlix JL, Godet J, Ivanyi-Nagy R, Fosse P, Mauffret O, Mely Y: Flexible nature and specific functions of the HIV-1 nucleocapsid protein. J Mol Biol 2011, 410:565-581.

4. Wu X, Liu H, Xiao H, Conway JA, Hehl E, Kalpana GV, Prasad V, Kappes JC: Human immunodeficiency virus type 1 integrase protein promotes 
reverse transcription through specific interactions with the nucleoprotein reverse transcription complex. J Virol 1999, 73:2126-2135.

5. Gleenberg 10 , Herschhorn A, Hizi A: Inhibition of the activities of reverse transcriptase and integrase of human immunodeficiency virus type- 1 by peptides derived from the homologous viral protein $\mathrm{R}(\mathrm{Vpr})$. J Mol Biol 2007, 369:1230-1243.

6. Harrich D, Ulich C, Garcia-Martinez LF, Gaynor RB: Tat is required for efficient HIV-1 reverse transcription. Embo J 1997, 16:1224-1235.

7. Henriet $S$, Sinck L, Bec G, Gorelick RJ, Marquet R, Paillart JC: Vif is a RNA chaperone that could temporally regulate RNA dimerization and the early steps of HIV-1 reverse transcription. Nucleic Acids Res 2007, 35:5141-5153.

8. Aiken C, Trono D: Nef stimulates human immunodeficiency virus type 1 proviral DNA synthesis. J Virol 1995, 69:5048-5056.

9. Fournier C, Cortay JC, Carbonnelle C, Ehresmann C, Marquet R, Boulanger P: The HIV-1 Nef protein enhances the affinity of reverse transcriptase for RNA in vitro. Virus Genes 2002, 25:255-269.

10. Nascimbeni M, Bouyac M, Rey F, Spire B, Clavel F: The replicative impairment of Vif- mutants of human immunodeficiency virus type 1 correlates with an overall defect in viral DNA synthesis. J Gen Virol 1998, 79:1945-1950

11. Warrilow D, Harrich D: HIV-1 replication from after cell entry to the nuclear periphery. Curr HIV Res 2007, 5:293-299.

12. Warrilow D, Stenzel D, Harrich D: Isolated HIV-1 core is active for reverse transcription. Retrovirology 2007, 4:77.

13. Zhang H, Dornadula G, Orenstein J, Pomerantz RJ: Morphologic changes in human immunodeficiency virus type 1 virions secondary to intravirion reverse transcription: evidence indicating that reverse transcription may not take place within the intact viral core. J Hum Virol 2000, 3:165-172

14. Warrilow D, Meredith L, Davis A, Burrell C, Li P, Harrich D: Cell factors stimulate human immunodeficiency virus type 1 reverse transcription in vitro. J Virol 2008, 82:1425-1437.

15. Forshey BM, von Schwedler U, Sundquist WI, Aiken C: Formation of a human immunodeficiency virus type 1 core of optimal stability is crucial for viral replication. J Virol 2002, 76:5667-5677.

16. Warrilow D, Warren K, Harrich D: Strand transfer and elongation of HIV-1 reverse transcription is facilitated by cell factors in vitro. PLOS ONE 2010, 5:e13229.

17. Hamamoto S, Nishitsuji H, Amagasa T, Kannagi M, Masuda T: Identification of a novel human immunodeficiency virus type 1 integrase interactor, Gemin2, that facilitates efficient viral cDNA synthesis in vivo. J Virol 2006, 80:5670-5677.

18. Nishitsuji H, Hayashi T, Takahashi T, Miyano M, Kannagi M, Masuda T: Augmentation of reverse transcription by integrase through an interaction with host factor, SIP1/Gemin2 Is critical for HIV-1 infection. PLOS ONE 2009, 4:e7825.

19. Rain JC, Cribier A, Gerard A, Emiliani S, Benarous R: Yeast two-hybrid detection of integrase-host factor interactions. Methods 2009, 47:291-297.

20. Kalpana GV, Marmon S, Wang W, Crabtree GR, Goff SP: Binding and stimulation of HIV-1 integrase by a human homolog of yeast transcription factor SNF5. Science 1994, 266:2002-2006

21. Sorin M, Cano J, Das S, Mathew S, Wu X, Davies KP, Shi X, Cheng SW, Ott D, Kalpana GV: Recruitment of a SAP18-HDAC1 complex into HIV-1 virions and its requirement for viral replication. PLOS Pathog 2009, 5:e1000463.

22. Takahashi H, Matsuda M, Kojima A, Sata T, Andoh T, Kurata T, Nagashima K, Hall WW: Human immunodeficiency virus type 1 reverse transcriptase: enhancement of activity by interaction with cellular topoisomerase I. Proc Natl Acad Sci U S A 1995, 92:5694-5698.

23. Roy BB, Hu J, Guo X, Russell RS, Guo F, Kleiman L, Liang C: Association of RNA helicase a with human immunodeficiency virus type 1 particles. J Biol Chem 2006, 281:12625-12635.

24. Warren K, Wei T, Li D, Qin F, Warrilow D, Lin MH, Sivakumaran H, Apolloni A, Abbott CM, Jones A, et al: Eukaryotic elongation factor 1 complex subunits are critical HIV-1 reverse transcription cofactors. Proc Natl Acad Sci U S A 2012, 109:9587-9592.

25. Konig R, Zhou Y, Elleder D, Diamond TL, Bonamy GM, Irelan JT, Chiang CY, Tu BP, De Jesus PD, Lilley CE, et al: Global analysis of host-pathogen interactions that regulate early-stage HIV-1 replication. Cell 2008 , 135:49-60.

26. Zhou H, Xu M, Huang Q, Gates AT, Zhang XD, Castle JC, Stec E, Ferrer M, Strulovici B, Hazuda DJ, Espeseth AS: Genome-scale RNAi screen for host factors required for HIV replication. Cell Host Microbe 2008, 4:495-504.
27. Brass AL, Dykxhoorn DM, Benita Y, Yan N, Engelman A, Xavier RJ, Lieberman J, Elledge SJ: Identification of host proteins required for HIV infection through a functional genomic screen. Science 2008, 319:921-926.

28. Lemay J, Maidou-Peindara P, Cancio R, Ennifar E, Coadou G, Maga G, Rain JC, Benarous R, Liu LX: AKAP149 binds to HIV-1 reverse transcriptase and is involved in the reverse transcription. J Mol Bio/ 2008, 383:783-796.

29. Zhang H, Yang B, Pomerantz RJ, Zhang C, Arunachalam SC, Gao L: The cytidine deaminase CEM15 induces hypermutation in newly synthesized HIV-1 DNA. Nature 2003, 424:94-98.

30. Mangeat B, Turelli P, Caron G, Friedli M, Perrin L, Trono D: Broad antiretroviral defence by human APOBEC3G through lethal editing of nascent reverse transcripts. Nature 2003, 424:99-103.

31. Lecossier D, Bouchonnet F, Clavel F, Hance AJ: Hypermutation of HIV-1 DNA in the absence of the Vif protein. Science 2003, 300:1112

32. Iwatani Y, Chan DS, Wang F, Maynard KS, Sugiura W, Gronenborn AM, Rouzina I, Williams MC, Musier-Forsyth K, Levin JG: Deaminase-independent inhibition of HIV-1 reverse transcription by APOBEC3G. Nucleic Acids Res 2007, 35:7096-7108.

33. Bishop KN, Verma M, Kim EY, Wolinsky SM, Malim MH: APOBEC3G inhibits elongation of HIV-1 reverse transcripts. PLoS Pathog 2008, 4:e1000231.

34. Cartier C, Hemonnot B, Gay B, Bardy M, Sanchiz C, Devaux C, Briant L: Active CAMP-dependent protein kinase incorporated within highly purified HIV-1 particles is required for viral infectivity and interacts with viral capsid protein. J Biol Chem 2003, 278:35211-35219.

35. Giroud C, Chazal N, Briant L: Cellular kinases incorporated into HIV-1 particles: passive or active passengers? Retrovirology 2011, 8:71

36. Harris TE, Persaud SJ, Jones PM: Pseudosubstrate inhibition of cyclic AMPdependent protein kinase in intact pancreatic islets: effects on cyclic AMP-dependent and glucose-dependent insulin secretion. Biochem Biophys Res Commun 1997, 232:648-651.

37. Hachiya A, Aizawa-Matsuoka S, Tanaka M, Takahashi Y, Ida S, Gatanaga H, Hirabayashi Y, Kojima A, Tatsumi M, Oka S: Rapid and simple phenotypic assay for drug susceptibility of human immunodeficiency virus type 1 using CCR5-expressing HeLa/CD4(+) cell clone 1-10 (MAGIC-5). Antimicrob Agents Chemother 2001, 45:495-501.

38. Rabbi MF, Saifuddin M, Gu DS, Kagnoff MF, Roebuck KA: U5 region of the human immunodeficiency virus type 1 long terminal repeat contains TRE-like CAMP-responsive elements that bind both AP-1 and CREB/ATF proteins. Virology 1997, 233:235-245.

39. Kemp BE, Pearson RB, House CM: Pseudosubstrate-based peptide inhibitors. Methods Enzymol 1991, 201:287-304.

40. Davis AJ, Carr JM, Bagley CJ, Powell J, Warrilow D, Harrich D, Burrell CJ, Li P. Human immunodeficiency virus type-1 reverse transcriptase exists as post-translationally modified forms in virions and cells. Retrovirology 2008, 5:115.

41. Lazaro JB, Boretto J, Selmi B, Capony JP, Canard B: Phosphorylation of AZTresistant human immunodeficiency virus type 1 reverse transcriptase by casein kinase II in vitro: effects on inhibitor sensitivity. Biochem Biophys Res Commun 2000, 275:26-32.

42. Idriss H, Kawa S, Damuni Z, Thompson EB, Wilson SH: HIV-1 reverse transcriptase is phosphorylated in vitro and in a cellular system. Int J Biochem Cell Biol 1999, 31:1443-1452.

43. Barnitz RA, Wan F, Tripuraneni V, Bolton DL, Lenardo MJ: Protein kinase A phosphorylation activates Vpr-induced cell cycle arrest during human immunodeficiency virus type 1 infection. J Virol 2010, 84:6410-6424

44. Li PL, Wang T, Buckley KA, Chenine AL, Popov S, Ruprecht RM: Phosphorylation of HIV Nef by cAMP-dependent protein kinase. Virology 2005, 331:367-374

45. Shirakawa K, Takaori-Kondo A, Yokoyama M, Izumi T, Matsui M, lo K, Sato T, Sato H, Uchiyama T: Phosphorylation of APOBEC3G by protein kinase A regulates its interaction with HIV-1 Vif. Nat Struct Mol Biol 2008, 15:1184-1191.

46. Brun S, Solignat M, Gay B, Bernard E, Chaloin L, Fenard D, Devaux C, Chazal N, Briant L: VSV-G pseudotyping rescues HIV-1 CA mutations that impair core assembly or stability. Retrovirology 2008, 5:57.

47. Amella CA, Sherry B, Shepp DH, Schmidtmayerova H: Macrophage inflammatory protein 1alpha inhibits postentry steps of human immunodeficiency virus type 1 infection via suppression of intracellular cyclic AMP. J Virol 2005, 79:5625-5631.

48. Hofmann B, Nishanian P, Nguyen T, Liu M, Fahey JL: Restoration of T-cell function in HIV infection by reduction of intracellular CAMP levels with adenosine analogues. Aids 1993, 7:659-664. 
49. Nokta M, Pollard R: Human immunodeficiency virus infection: association with altered intracellular levels of CAMP and CGMP in MT-4 cells. Virology 1991, 181:211-217.

50. Aukrust P, Aandahl EM, Skalhegg BS, Nordoy I, Hansson V, Tasken K, Froland SS, Muller F: Increased activation of protein kinase A type I contributes to the T cell deficiency in common variable immunodeficiency. J Immunol 1999, 162:1178-1185.

51. Aandahl EM, Aukrust P, Skalhegg BS, Muller F, Froland SS, Hansson V, Tasken K: Protein kinase A type I antagonist restores immune responses of T cells from HIV-infected patients. Faseb J 1998, 12:855-862.

52. Kagnoff MF, Roebuck KA: Human immunodeficiency virus type 1 (HIV-1) infection and expression in intestinal epithelial cells: role of protein kinase A and C pathways in HIV-1 transcription. J Infect Dis 1999, 179(Suppl 3):S444-S447.

53. Nokta MA, Pollard RB: Human immunodeficiency virus replication: modulation by cellular levels of cAMP. AIDS Res Hum Retroviruses 1992, 8:1255-1261.

54. Fenard D, Houzet L, Bernard E, Tupin A, Brun S, Mougel M, Devaux C, Chazal N, Briant L: Uracil DNA Glycosylase 2 negatively regulates HIV-1 LTR transcription. Nucleic Acids Res 2009, 37:6008-6018.

55. Krolczyk AJ, Bear CE, Lai PF, Schimmer BP: Effects of mutations in cAMP-dependent protein kinase on chloride efflux in Caco-2 human colonic carcinoma cells. J Cell Physiol 1995, 162:64-73.

doi:10.1186/1742-4690-10-157

Cite this article as: Giroud et al:: HIV-1-associated PKA acts as a cofactor for genome reverse transcription. Retrovirology 2013 10:157.

\section{Submit your next manuscript to BioMed Central and take full advantage of:}

- Convenient online submission

- Thorough peer review

- No space constraints or color figure charges

- Immediate publication on acceptance

- Inclusion in PubMed, CAS, Scopus and Google Scholar

- Research which is freely available for redistribution 